\title{
Rough sets of multi-granulation with topological approaches based kinds of neighborhood systems
}

\author{
mohammed atef ${ }^{1}$, Abd El Fattah El Atik ${ }^{2}$, and Ashraf Nawar ${ }^{1}$ \\ ${ }^{1}$ Menoufia University \\ ${ }^{2}$ Tanta University
}

May 5, 2020

\begin{abstract}
Recently, much attention has been given to multi-granulation rough sets (briefly, MGRS) and different kinds of multi-granulation rough set models have been developed from various viewpoints. In this paper, we propose two types of MGRS models under neighborhood systems from the topological view, where a target concept is approximated by employing the j-neighborhoods and j-adhesion neighborhoods of objects in a given universe set. Therefore, we investigate some of the basic properties of the two types of MGRS models and discuss the relationships and differences among the classical MGRS model and some other new models. Also, for each new MGRS model, an algorithm will be presented.
\end{abstract}

\section{Hosted file}

MGRS and MGTRS by NS.pdf available at https://authorea.com/users/299659/articles/429149rough-sets-of-multi-granulation-with-topological-approaches-based-kinds-of-neighborhoodsystems 